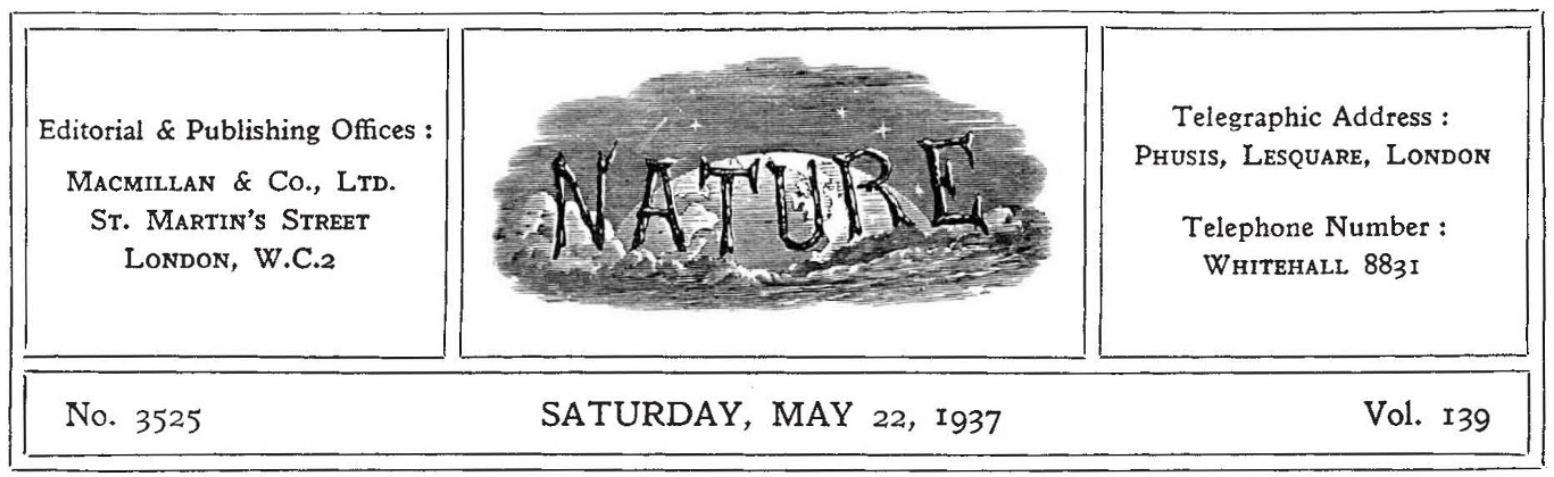

\title{
Health and Safety of Industrial Workers
}

$\mathrm{T}$ HE centenary of the Factory Act in 1935 led to a good deal of attention being directed to the inadequacy of the Factory and Workshops Act, 1901, which is largely obsolete, and the need for a new Act for the regulation of industry in Great Britain has been widely admitted during the last fifteen years both inside and outside Parliament. More than once, indeed, bills have been introduced; only to be laid on one side in favour of other matters said to be more pressing.

If, however, a new factory act is essential from the point of view of industry, it is, as a recent broadsheet entitled "Industry and Health" recently issued by Political and Economic Planning (P.E.P.) emphasizes, from the point of view of health and safety in industry that it derives its greatest importance, and additional interest is attached to the new Factory Bill in view of the present concern for the physical condition of the nation. Physical culture may be invaluable as a means of maintaining or improving health. It cannot be a remedy for injuries to health which are inflicted by such conditions as bad housing, overcrowding, malnutrition or unhealthy and dangerous conditions of work. The attempt to improve the physical condition of the people means, accordingly, not merely a campaign for physical education, but also a determined and simultaneous attack on all factors undermining the health of the community whether at work or at home.

It has to be recognized in the first place that although, during the nineteenth century, broadly speaking, Great Britain led the world in imposing the observance of minimum standards of safety, health, hours and conditions of employment in factories and workshops, during the twentieth century we have permitted the country to lag behind in these vital matters. Several industrial nations in Europe and in America have surpassed us in the solicitude they show towards their workers. Accordingly, the new Bill cannot be considered only in terms of the improvements it introduces. We must also have regard to the extent to which it remedies the relatively backward state into which our labour code has fallen during the last two or three decades.

Acts of Parliament, moreover, though invaluable for establishing effective minimum standards, and for rounding up laggards, have their limitations as methods of promoting reform. It is impracticable to enforce at any time standards substantially higher than those which the majority of firms adopt or are ready to adopt. The minimum standards prescribed by law may in fact be, and often are, far below those adopted by the more progressive and enlightened industrial units : and the spread of more enlightened methods must to a large extent precede the prohibition of those that are considered unsatisfactory.

It is this fact which makes such legislation of special interest to the scientific worker. While the improvements which the Bill will effect in working conditions will depend largely on the administration, owing to the wide powers given to the Secretary of State in limiting, extending or modifying its provisions, vigilance will be demanded both during and after the passage of the measure to ensure that its intentions are implemented. A large share of responsibility for this vigilance must rest upon scientific workers. Only if they are prepared to make their contribution can we expect the full effect of the new Bill to be realized - securing a genuine advance in the conditions of health and safety not merely within industry but 
also indirectly in the health of the nation as a whole.

The significance of the contribution of the scientific worker will be best appreciated if we recall first the immense superiority of labour conditions among the progressive firms over the majority, not merely the most backward; a superiority which is largely to be attributed to the more scientific outlook on the part of the managerial staff in such firms. It is further illustrated by the enormously greater incidence of industrial accidents among smaller firms where adequate scientific and technical supervision is lacking, as is shown by the annual reports of H.M. Chief Inspectors of Factories. In fact, the safety provisions of the new Bill are probably its best feature, but their efficacy will largely depend as much upon effective technical supervision and control within industry itself, particularly in the smaller firms, as upon an extension of the factory inspectorate commensurate with its greater responsibilities.

This question of health and safety in industry does not derive its whole interest from the new Factory Bill. The revival of heavy industry, and the re-employment of men who through their unemployment have lost some of their dexterity, make it probable that accident rates will rise even higher than they did last year. The tendency of armament firms under Government pressure to work night shifts and overtime will increase the danger. Moreover, the cost to industry of illhealth, whether due to unsatisfactory conditions such as long hours or poor lighting, or to the nature of the process, is already so high that little further stimulus to improvement should indeed be necessary. It was estimated by the Home Office that in 1934 industry spent nearly $£ 11,000,000$ in providing for its liabilities under the Workmen's Compensation Acts. The total number of working weeks lost annually by employees covered by National Health Insurance is estimated at thirty millions, equivalent to an entire year's work of some 600,000 persons. Moreover, any attempt to assess the burden of ill-health to industry must also allow for the losses from labour turnover through unhealthy conditions from inefficiency, due to the same cause among those actually at work.

The vital problem at the moment in industrial health is labour conditions, especially hours of work, the length of which is only restricted by law in four industries, the most important being coal-mining and road transport. In these respects, the Bill falls lamentably short of the recommendations of the report of the Departmental Committee on the Hours of Employment of Young Persons. That this position should be arising eighteen years after the work of the Health of Munition Workers Committee had demonstrated its detrimental effect on industrial output and efficiency indicates an astonishing lack of wise and scientific management. Moreover, it must be remembered that the existence of this position makes it much more difficult for the more enlightened firms to persist in their efforts to shorten the working week and to eliminate overtime. In addition, there is no adequate mechanism for ensuring that the results of research carried out by such bodies as the Industrial Health Research Board are considered and implemented.

When all due allowance is made for the natural time-lag between such research and its application in the improvement of factory conditions in respect of lighting, ventilation, humidity and air conditioning generally, there can be no doubt that the gap is excessive and very seriously detrimental to both industrial efficiency and the health of the workers. The minimum conditions laid down by the 1901 Act are antiquated and sometimes deficient, and although definite standards for different factories have sometimes been worked out, they are only enforced when the Secretary of State is satisfied that any trade is dangerous or unhealthy and where he can therefore issue special orders under the statute. The new Bill does include a clause providing that "sufficient and suitable lighting, whether natural or artificial" shall be maintained in every part of the factory. The new Bill also raises the standard of overcrowding from 250 cubic feet of space per worker to 400 cubic feet and contains general provisions regarding temperature and ventilation, although any standards are to be enforced by legislation. Specific provisions for the removal of dust and for the control of underground workrooms are included. Similarly under welfare there are general provisions regarding first-aid boxes, drinking water, and, in factories employing females, seats must be provided. Provision of washing facilities, rooms for drying clothes, and mess rooms for employees are only compulsory if special orders are made by the Secretary of State.

It is thus evident that the new Bill makes a cautious but definite advance in dealing with the environmental defects and long hours in factories 
which tend to increase the incidence of diseases occurring in the rest of the community. Unfortunately, the progressive firms which have made a study of environmental conditions still cover only a small percentage of the population.

Similarly, the incidence of industrial accidents is greatest among the smaller firms, despite notable exceptions, and this problem is one that can scarcely be dealt with by legislation alone. Even a very great increase in the inspectorate would be unable by itself to cope with contravention of the law in respect of hours of work of young persons or ensure the strict observance of the new safety provisions. What is needed here is a significant increase in the extent of trained scientific supervision, competent to foresee dangers and to take the necessary precautions in advance and not merely as a sequel to some accident taking toll of life or limb. This is above all a matter for professional associations of scientific workers.

This aspect of the question becomes more important when we consider the relation of the Factory Department to the Home Office, and not to the Ministry of Health, which is concerned with most other medical services of the country. This system has been criticized as anomalous, and obviously close co-operation between the local medical officer of health and the various authorities concerned with the health and conditions of factory workers is extremely desirable. If, however, employees are to be kept in a good state of health, maximum industrial efficiency achieved, and the enormous expense caused by accidents and sickness saved, something much more than the minimum measures enforced by present legislation is required.

The most important need is in fact a considerable expansion of the medical services in industry itself which have already been introduced by a number of firms or industries, sometimes to deal with a particularly industrial hazard or high accident rate. Such services, moreover, are often organized to cover the medical examination of all employees from the point of view of their own health and, as in factories handling food, that of public health generally, and the whole tendency in industry is for this preventive medical service to increase. It is accordingly a disappointing feature of the present Bill that more is not done to make the medical examination of young persons a better protection for them.

It should not be forgotten that the medical services now developing in industry are responsible for an increasing amount of research aimed at the prevention and elimination of industrial hazards. This, of course, is not a matter for the medical officer alone. The chemist, the physicist, the engineer, the works or departmental manager have their own contributions to make, and the problem is one of organizing team work and co-operation in the most effective way. Nor should it be forgotten that questions of professional ethics and responsibility are also involved. The relationship between the general practitioner and the industrial medical officer now being worked out by a subcommittee of the Medico-Political Committee of the British Medical Association is only one aspect of the professional position of the medical officer in industry which equally applies to other types of scientific worker. The clash of loyalties which may quite easily arise is unlikely to be resolved without a definite and accepted ethical code.

The development and improvement of an industrial medical service in fact involves many extremely complex problems, including questions of co-operation between different industrial units. It is believed that unless there is a special occupational hazard, it is uneconomic to employ a fulltime medical officer where less than 5,000 persons are employed. Only about one per cent of the industrial population is found in factories of this size, yet smaller factories are confronted with many of the problems which the full-time industrial medical officer has to handle in a large firm. Moreover, there are still firms with high accident rates and specific occupational hazards employing more than 10,000 persons, which have no medical officer on the premises.

The new Factories Bill has accordingly very considerable claims on the interests of scientific workers. Upon their co-operation, both in a technical capacity, and as departmental managers or as members of the inspectorate itself, apart from participation in the considerable volume of research into problems of industrial safety and health still required, the real success of its aims in no small measure depends. Further, the very extent to which they have come to share in the direction and management of industry itself stresses their responsibility for effective and informed criticism of the new Bill, particularly where, as in regard to the provisions relating to the employment of young persons and particularly overtime, it is open to grave abuse and falls lamentably short of standards of enlightened practice of proved desirability. 